\title{
Wolbachia (Alphaproteobacteria: Rickettsiales) Infections in Isolated Aphid Populations from Oceanic Islands of the Azores Archipelago: Revisiting the Supergroups M and N
}

\author{
Marta Moreira, ${ }^{1,2}$ António M. F. Aguiar, ${ }^{3}$ Kostas Bourtzis, ${ }^{4}$ Amparo Latorre, ${ }^{5,6}$ and \\ Mahnaz Khadem ${ }^{1,7, \bullet}$
}

\begin{abstract}
'Banco de Germoplasma, Universidade da Madeira, Campus da Penteada 9020-105 Funchal, Portugal, ${ }^{2}$ Present address: Neurodevelopment Group, School of Biosciences, University of Birmingham, Edgbaston, Birmingham, UK, ${ }^{3}$ Laboratório de Qualidade agrícola, Núcleo de Fitopatologia, Madeira, Portugal, ${ }^{4}$ Insect Pest Control Laboratory, Joint FAO/IAEA Division of Nuclear Techniques in Food and Agriculture, Vienna, Austria, ${ }^{5}$ Institute for Integrative Systems Biology (University of ValenciaCSIC), Valencia, Spain, ${ }^{6}$ Joint Unit in Genomics and Health, Foundation for the Promotion of Sanitary and Biomedical Research (FISABIO) and University of Valencia, Valencia, Spain, and ${ }^{7}$ Corresponding author, e-mail: khadem@uma.pt
\end{abstract}

Subject Editor: Jiri Hulcr

Received 6 July 2018; Editorial decision 11 December 2018

\begin{abstract}
Aphids (Hemiptera: Aphididae) have provided a suitable model to study endosymbionts, their community, and dynamics since the discovery of the obligate endosymbiont Buchnera aphidicola in these organisms. In previous studies, Wolbachia was found in some aphid species. In the present study, we report the prevalence of Wolbachia in aphids sampled from a geographically isolated region (Azores Islands), aiming at a better understanding and characterization of the two newly reported supergroups, $\mathrm{M}$ and $\mathrm{N}$. The description of the supergroup $\mathrm{M}$ was based on $16 S$ rRNA as well as some protein-coding genes. However, the assignment of the supergroup $\mathrm{N}$ was according to $16 S$ rRNA gene sequences of a very few samples. We collected aphid samples and performed phylogenetic analysis of $16 S$ rRNA gene as well as four protein-coding genes (gat $B, f t s Z, \operatorname{cox} A$, and $h c p A$ ). The results demonstrate that the $16 S$ rRNA gene data can unambiguously assign the strain supergroup and that the two supergroups, $N$ and $M$, are equally prevalent in Azorean aphids. The available sequence data for the protein-coding markers can identify supergroup $M$ but the status of supergroup $N$ is inconclusive, requiring further studies. The data suggest that horizontal transmission of Wolbachia (Hertig and Wolbach) between two phylogenetically distant aphid species cohabiting the same plant host.
\end{abstract}

Key words: endosymbiosis, phylogenetic analysis, protein-coding genes and 16S rRNA genes

Many arthropods have developed close relationships with plants which they feed upon; therefore, they can cause direct damage to their hosts by depleting nutrients or/and can be harmful by transmitting disease to their hosts (Perilla-Henao and Casteel 2016). On the other hand, arthropods have also developed a variety of symbiotic associations, with their intracellular microorganisms (endosymbionts) that can provide an effective system to control pest and disease vector populations (Saridaki and Bourtzis 2010, Bourtzis et al. 2014).

The endosymbionts that provide essential nutrients for the hosts, thus indispensable for their survival are referred as primary or obligate endosymbionts. Additionally, may harbor secondary facultative endosymbionts that can be dispensable, although under certain circumstances they can provide some benefits to their hosts and/ or modify their biology (Engelstädter and Hurst 2006, Oliver et al. 2010, Oliver et al. 2014). The secondary endosymbionts, in some cases, can modify and turn into obligate ones (reviewed in Moya et al.
2008). The best studied facultative endosymbionts are Wolbachia; these Alphaproteobacterial are widely spread in diverse invertebrate groups (Zug and Hammerstein 2012). They are primarily transmitted vertically from mother to offspring, although horizontal mode of transmission has also been reported (Stouthamer et al. 1999, Russell et al. 2003, Ahmed et al. 2015). Based on phylogenetic studies, Wolbachia have been divided into distinct monophyletic lineages known as supergroups (Zhou et al. 1998, Baldo et al. 2006, Lo et al. 2007) and so far, 16 Wolbachia supergroups are described: A-Q (except $\mathrm{G}$ that is, in fact, a combination of A and B) (Augustinos et al. 2011, Bing et al. 2014, Glowska et al. 2015). A new supergroup (R) was proposed by Wang et al. (2016) in cave spider species, however, this designation was challenged by another study after reanalyzing the data (Gerth 2016). Depending on the bacterial type and the host-Wolbachia symbiotic association, the symbiont can influence their host's biology in numerous manners including the induction 
of several reproductive anomalies (cytoplasmic incompatibility, male killing, feminization, etc.) (Breeuwer and Werren 1990, Stouthamer et al. 1990, Werren et al. 2008), but also positive effects, including nutritional role, are found (Nikoh et al. 2014, Akoundi et al. 2016). Thus, strain typing is essential in understanding the genetic structure, evolution, and biology of the bacteria.

Aphids are a highly diversified and widely distributed group of insects (Blackman and Eastop 1984); these plant sap-feeding insects can cause severe damage to plants. Aphids have evolved very close associations with bacterial endosymbionts. Their success may have been related to their ability to use a large variety of plants or/and acquiring endosymbionts. The primary endosymbionts of aphids, Buchnera aphidicola, provide some essential nutrients that are lacking in their unbalanced diet (Hansen and Moran 2011). Until now, up to nine secondary or facultative symbionts have been reported in aphids (reviewed in Guo et al. 2017). Depending on their type, the bacteria may benefit the host in diverse ways such as heat shock resistance, parasitoid wasp resistance, fungi resistance, enhancement of host plant fitness, and favoring the supply of essential nutrients with another co-obligatory symbiont (Chen et al. 2000, Oliver et al. 2003, Gómez-Valero et al. 2004, Oliver et al. 2005, Scarborough et al. 2005, Lukasik et al. 2013a, De Clerck et al. 2015). They can also have negative impact in the host by reducing the host's longevity, host plant fitness, etc., (Chen et al. 2000, Simon et al. 2007, Polin et al. 2014). Some secondary endosymbionts, such as Serratia symbiotica and Wolbachia, can potentially provide nutrition to the host (Koga et al. 2003, Pérez-Brocal et al. 2006, Koga et al. 2007, De Clerck et al. 2015). A single symbiont might influence the host in diverse manners and a single host might carry several symbiont species interacting with each other and influencing the host biology (Tsuchida et al. 2004, Oliver et al. 2010, Russell et al. 2013, Lukasik et al. 2013b, Oliver et al. 2014, Heyworth and Ferrari 2015, Leclair et al. 2016a). Moreover, change in symbiotic status (secondary or facultative to primary or obligate) in some aphid species has also been reported (Lamelas et al. 2008, Lamelas et al. 2011, ManzanoMarín and Latorre 2014, Latorre and Manzano-Marín 2017). The first report on the presence of a Wolbachia strain in an aphid species, Cinara cedri, was in 2004 (Gómez-Valero et al. 2004). However, until recently Wolbachia infections were considered rare in aphids, but a different picture was emerged by two recent studies of European and Chinese populations (Augustinos et al. 2011, Wang et al. 2014). Augustinos et al. (2011) identified the two already described supergroups ( $\mathrm{A}$ and $\mathrm{B}$ ) and characterized two new ones ( $\mathrm{M}$ and $\mathrm{N}$ ) in 425 European samples representing 144 species, while Wang et al. (2014) detected three supergroups (A, B, and M) in 109 samples representing 73 species. The infection rate was unprecedently high in Chinese populations (100\%), while only $8.7 \%$ (37 of 425 samples) of the European populations harbored Wolbachia. In both studies, the supergroup $M$ was the most prevalent in aphids. Wang et al. (2014) hypothesized that this supergroup spread recently and rapidly in aphids from China. Despite the high rate of infection and elevated number of samples studied, supergroup $\mathrm{N}$ was not detected in Chinese populations. On the other hand, in European populations $\mathrm{N}$ supergroup was only detected in three samples, representing two species (Toxoptera aurantii and Neophyllapis podocarpi), collected from two of the Azorean Islands (Terceira and São Miguel in April 2009 and September 2010, respectively). Thus, so far, Azores is the only geographical area where supergroup $\mathrm{N}$ has been found. Supergroup M was the only other supergroup detected in four of Azorean samples representing one species of Aphidinae.

Due to geographical isolation and predicted population size reduction of the founders, we expect to detect less strain types in island compared to mainland, but also the occurrence of new isolates in island is quite possibly due to the novel ecological conditions that the host is subjected to. To better understand the prevalence and types of Wolbachia in aphid populations from the Azorean Archipelago, in this study, we characterize the bacteria strains using gene fragments of the coxA, ftsZ, gatB, and $h c p A$ genes in 115 aphid samples collected in three Azorean islands (São Miguel, São Jorge, and Pico).

\section{Materials and Methods}

\section{Aphids Collection}

Aphids were collected in June 2012 from three of the nine islands of the Azores Archipelago, in the Atlantic Ocean (Supp Fig. S1). The nearest island to the mainland is about $1.600 \mathrm{~km}$ west of the coast of Portugal. The collection sites, aphid family, species, and their host plants are presented in Supp Table S1. Aphids were kept in $100 \%$ ethanol at $-20^{\circ} \mathrm{C}$ until their DNA extraction. The aphids' identification was based on the dichotomous keys provided by Blackman and Eastop (1989, 1994). A total of 115 aphid samples representing 18 species were collected. From these samples, 89 belonged to Aphidinae subfamily (16 species); 21 to Lachininae subfamily ( 3 species); and 5 to Drepanosiphinae subfamily (1 species). Aphis fabae was the most abundant species (20 samples) followed by Aphis spiraecola (16 samples), Toxoptera aurantii (15 samples), Aphis gossypii (8 samples), N. podocarpi (5 samples), and Aphis hederae (4 samples) (Table 1). Other species were represented only by one or two samples. Eleven samples of the Aphidinae subfamily and 14 of the Lachininae subfamily were not identified at species level (Supp Table S1). Two samples collected in Barcelona from two adjacent Podocarpus trees were identified as $N$. podocarpi and were also included in the analysis.

\section{DNA Extraction and Wolbachia Detection}

DNA was extracted from a group of four individuals based on the protocol described in Latorre et al. (1986). Presence or absence of Wolbachia in aphids was based on PCR amplification of 16S $r$ RNA gene. After many trials and difficulties in amplifying a full-length gene, we opted to use two Wolbachia-specific primers (wspecF, the first nucleotide modified from $\mathrm{C}$ to $\mathrm{Y}$, and wspecR). Although the size of PCR product was small (about 441 base pairs [bp]), these primers successfully and repeatedly amplified the infected samples, an impossible task when other primer pairs were used. The PCR conditions and the primers used are given in Supp Table S2. Both strands were cycle-sequenced using BigDyeTM Terminators 3.1 Kit (Applied Biosystems) and run on an ABI Prism 3700 sequencer by Stabvida Inc.

\section{Amplification of MLST Gene Fragments}

The samples that amplified the 16S rRNA gene fragment were considered Wolbachia infected and their sequences were used to characterize the strain. The following MLST genes were amplified: $f t s Z$ (cell division protein), $\operatorname{cox} A$ (cytochrome c oxidase subunit I), $h c p A$ (hypothetic conservative protein), and gatB (glutamyl-tRNA aminotransferase subunit $\mathrm{B}$ ). The amplification conditions and primers were as given in Baldo et al. (2006) and Augustinos et al. (2011), with some optimization in annealing temperatures (Supp Table S2).

\section{Cloning and Sequencing}

The amplicons were purified using NucleoFast 96 PCR plates (Macherey-Nagel) before being ligated into a T-vector (pGEM-T Easy) and transformed into competent cells according to the manufacturer's instructions. Six transformed clones were used in PCR amplification by the primers T7 and SP6. BigDye Terminators 3.1 
Table 1. The infection rate of Wolbachia in aphid species and the supergroups of infected samples based on $16 S$ rRNA gene sequences

\begin{tabular}{|c|c|c|c|c|}
\hline Aphid subfamily Aphidinae & Aphid species & Number & $\%$ positives & Supergroups \\
\hline & Aphis fabae (Scopoli) & 20 & 0 & \\
\hline & Aphis spiraecola (Patch) & 16 & $43,7 \%(7)$ & $\mathrm{M}, \mathrm{N}$ \\
\hline & Toxoptera aurantii & 15 & 0 & \\
\hline & Aphis sp. & 10 & 0 & \\
\hline & Aphis gossypii (Golver) & 8 & 0 & \\
\hline & Aphis hederae (Kaltenbach) & 4 & $25 \%(1)$ & M, B \\
\hline & Aphis craccivora (Koch) & 3 & 0 & \\
\hline & Aphis nerii (Boyer de Fonscolombe) & 2 & 0 & \\
\hline & Aphis ruborum (Börner) & 2 & 0 & \\
\hline & Aphis oenotherae (Oestlund) & 1 & 0 & \\
\hline & Illinoia azalea (Mason) & 1 & 0 & \\
\hline & Illinoia lambersi (MacGillivary) & 1 & 0 & \\
\hline & Macrosiphum euphorbiae (Thomas) & 1 & 0 & \\
\hline & Macrosiphum rosae (Linnaeus) & 1 & 0 & \\
\hline & Melanaphis donacis (Passerini) & 1 & 0 & \\
\hline & Metopolophium dirhodum (Walker) & 1 & 0 & \\
\hline & Uroleucon sp. (Mordvilko) & 1 & 0 & \\
\hline & NI & 1 & 1 & \\
\hline & Total & 89 & $10(9)$ & \\
\hline \multicolumn{5}{|l|}{ Drepanosiphinae } \\
\hline & Neophyllaphis podocarpi (Takahashi) & 5 & $100 \%(5)$ & $\mathrm{N}$ \\
\hline & N. podocarpi (Barcelona) & 2 & $100 \%(2)$ & M \\
\hline & Total & 7 & $100 \%$ & \\
\hline \multicolumn{5}{|l|}{ Lachninae } \\
\hline & Cinara sp. (Miller) & 20 & 0 & \\
\hline & Eulachnus rileyi (Williams) & 1 & 0 & \\
\hline & Total & 21 & 0 & \\
\hline & Total number of Azorean samples screened & 115 & $12 \%(14)$ & \\
\hline
\end{tabular}

Number of infected aphids is shown in ().

Kit (Applied Biosystems) and run on an ABI Prism 3700 sequencer by STABVIDA Inc. The obtained sequences were first viewed in BioEdit 7.0.5.3 (Hall 1999), then assembled and edited using the SeqMan program of the DNASTAR Lasergene software package. ClustalW (Thompson et al. 1994) was used to align sequences obtained in this work, together with other related sequences deposited in the GenBank database. The aligned sequences were edited with MacClade (version 4.0) (Maddison and Maddison 2000). The alignment lengths were 441 bp, 369 bp, 414 bp, 402 bp, and 444 bp for $16 S r R N A, g a t B, f t s Z$, coxA, and hcpA genes, respectively. All the sequences obtained in this study are deposited in the GenBank database under accession numbers MK053596 - MK053608.

\section{Genetic Distance and Phylogenetic Analysis}

The best fit model for each sequence data was determined using Akaike information criteria with the program MEGA version 6 (Tamura et al. 2013). To construct the phylogenetic tree, the following models were used: GTR $+\mathrm{G}+\mathrm{I}$ substitution model for $16 \mathrm{~S} r \mathrm{RNA}$ data, GTR+G substitution model for $\operatorname{cox} A$, gatB \& ftsZ data, and T92+G for $h c p A$ data. The trees were constructed using maximum likelihood (ML) method and the confidence level of the inferred topology was estimated by 1,000 bootstrap replicates in MEGA 6 . This program was also used to compare evolutionary divergence between the sequences using Kimura 2-parameter (K2P) distance model (Kimura 1980).

\section{Results}

\section{Occurrence of Wolbachia in Azorean Aphids}

The presence of Wolbachia was investigated in the samples using $16 S$ rRNA gene-specific primers and results showed that $12 \%$
(14 of 115) of the samples were infected by the bacterium. All the infected samples belonged to only three species: A. hederae, A. spiraecola, and $N$. podocarpi, although the infection rates were $25,43.7$, and $100 \%$, respectively (Table 1 ). The rate of infections also varied among the three islands: $14.8 \%$ in Pico (4 of 27) samples, $5.8 \%$ in São Jorge ( 2 of 34 ) samples, and $14.8 \%$ in S. Miguel (8 of 54) samples. Augustinos et al. (2011) reported that only $3.7 \%$ (1 of 27) samples from São Miguel were infected while the rate of infection was $15 \%$ (6 of 40 ) in another Azorean Island (Terceira).

\section{Strain Typing and Phylogenetic Analysis}

To perform strain typing, the samples identified as infected were amplified for $\operatorname{cox} A, f t s Z$, gat $B$, and $h c p A$ gene fragments. Despite many efforts, we were unable to PCR amplify and sequence all the infected samples for the mentioned gene fragments. Some of the gene fragments could be successfully amplified and sequenced in some of the samples but not in others (Table 2). The difficulties of Wolbachia strain typing in aphids have also been reported earlier (Augustinos et al. 2011, Wang et al. 2014).

The phylogeny of $16 S r R N A$ gene sequences shows that all the samples of $N$. podocarpi were infected by Wolbachia belonging to two supergroups: $\mathrm{M}$, in the two samples collected in Barcelona and $\mathrm{N}$, in samples collected from different localities of S. Miguel Island, Azores (Fig. 1). The N. podocarpi Chinese samples harbored supergroups $\mathrm{M}$ and $\mathrm{A}$ (Wang et al. 2014). One of the samples of A. spiraecola (collected in a different island) clusters with $N$. podocarpi in supergroup N. Three A. spiraecola samples belonging to supergroup $\mathrm{M}$ and one sample of $A$. hederae were infected by $\mathrm{M}$ and $\mathrm{B}$ supergroups (AZ 136 and AZ 136-1). 
Table 2. Aphid samples positives for Wolbachia and PCR amplification results for $16 S$ rRNA and MLST genes

\begin{tabular}{|c|c|c|c|c|c|c|c|c|}
\hline \multirow[t]{2}{*}{ Samples } & \multirow[t]{2}{*}{ Plant host } & \multirow[t]{2}{*}{ Aphid subfamily } & \multirow[t]{2}{*}{ Aphid species } & \multirow[t]{2}{*}{$16 S r R N A$} & \multicolumn{4}{|c|}{ MLST } \\
\hline & & & & & gatB & $f t s Z$ & $\operatorname{cox} A$ & $h c p A$ \\
\hline AZ 80 & $\begin{array}{l}\text { Pyracantha angustifolia } \\
\text { (Schneid) }\end{array}$ & Aphidinae & Aphis spiraecola & + & + & - & - & - \\
\hline AZ 86 & Podocarpus sp. & Aphidinae & Aphis spiraecola & - & - & + & + & - \\
\hline AZ 100 & NI & Aphidinae & Aphis spiraecola & + & - & - & - & - \\
\hline AZ 102 & NI & Aphidinae & NI & + & + & - & - & - \\
\hline AZ 129 & Eriobotrya japonica (Lindl) & Aphidinae & Aphis spiraecola & + & + & - & - & - \\
\hline AZ 134 & Pyrcantha coccinea (Roem) & Aphidinae & Aphis spiraecola & + & + & - & - & - \\
\hline AZ 135 & Ilex perado azorica (Tutin) & Aphidinae & Aphis spiraecola & + & + & - & - & - \\
\hline AZ 136 & Hedera sp. (Campbell) & Aphidinae & Aphis hederae & + & - & + & + & - \\
\hline AZ 184 & $\begin{array}{l}\text { Pyrcantha angustifolia } \\
\text { (Schneid) }\end{array}$ & Aphididnae & Aphis spiraecola & + & - & - & - & - \\
\hline AZ 81 & Podocarpus sp. & Drepanosiphinae & Neophyllaphis podocarpi & + & - & + & + & + \\
\hline AZ 85 & Podocarpus sp. & Drepanosiphinae & Neophyllaphis podocarpi & + & - & + & + & - \\
\hline AZ 162 & Podocarpus sp. & Drepanosiphinae & Neophyllaphis podocarpi & + & + & + & + & - \\
\hline AZ 172 & Podocarpus sp. & Drepanosiphinae & Neophyllaphis podocarpi & - & + & + & - & + \\
\hline AZ 181 & Podocarpus sp. & Drepanosiphinae & Neophyllaphis podocarpi & + & - & - & - & + \\
\hline
\end{tabular}

NI, not identified; +, amplified; -, not amplified.

Then, we performed phylogenetic analysis for other gene markers (either separately or combined). In gatB phylogenetic tree, the samples from supergroup $M$ clustered together and well separated from other supergroups, while those representing supergroup $\mathrm{N}$ (namely N. podocarpi) although clustered together, the cluster was localized within supergroup B (Supp Fig. S2a). The same typology is observed in $f t s Z$ phylogenetic tree (Supp Fig. S2b). More complex phylogenetic relations emerged in $\operatorname{coxA}$ analysis (Supp Fig. S2c): cluster 1 includes the sequences from supergroups $\mathrm{M}, \mathrm{N}$, and $\mathrm{B}$ (based on $16 \mathrm{~S}$ $r R N A$ gene data); clusters 2 and 3 include the sequences representing exclusively supergroup $B$, although cluster 2 occupies an intermediate position between clusters 1 and 3. Both in fts $Z$ and coxA phylogenetic trees, one sample of $A$. spireacola (AZ-86) grouped with samples of $N$. podocarpi. Interestingly, this sample and N. podocarpi (AZ-85) were taken from the same host plant (Podocarpus sp.). In these phylogenetic trees, A. hedera (AZ-136-1) is well positioned in supergroup B. Moreover, the position of C. cedri from Spain (specially Salamanca strain) in the three phylogenetic trees should be noted, the $\operatorname{cox} A$ and gat $B$ sequences clustered in supergroupB, while in $f t s Z$ tree a separate clade (close to supergroup B) was found. For $h c p A$ gene, we could only obtain three sequences, all from $N$. podocarpi samples, which were clustered in supergroup B (Supp Fig. S2d).

We also performed phylogenetic analysis for concatenated data, with available sequences of the same strain for $16 S r R N A, f t s Z$ and coxA genes (Table 2). The tree shows (Fig. 2) that the Azorean samples of $N$. podocarpi are well separated from those of supergroup B as well as from C. cedri (Salamanca).

\section{Genetic Distances}

The pairwise genetic distances between the sequences mainly representing supergroups $\mathrm{B}, \mathrm{M}$, and $\mathrm{N}$ for each gene fragment and concatenated data are shown in Supp Table S3. In $16 S$ rRNA gene data, all the distances between the supergroups are above $2 \%$, the value required for separating the supergroups (Breeuer et al. 1992, Stouthamer et al. 1993). The genetic distances are higher between $\mathrm{N}$ \& $\mathrm{M}$ compared with $\mathrm{N} \& \mathrm{~B}$ supergroups.

Considering supergroups B-N, the pairwise distances are lower than $2 \%$ in three of the protein-coding genes ( $f t s Z$, gat B, and $h c p A$ ), with one exception in $f t s Z$ data. In $\operatorname{cox} A$ data, the genetic distances are between zero to $8.9 \%$ depending on the Wolbachia strains. Very low values $(<1 \%)$ within cluster 1 (which includes different supergroups), intermediate values (about 3\%) between clusters 1 and 2 and high values (about $8 \%$ ) between clusters 1 and 3 . Thus, depending on the Wolbachia strain, the pairwise genetic distances can either support the separation of the strains in different supergroups or not. The pairwise genetic distances between supergroups N-M and M-B are above $20 \%$ in $f t s Z$ and gat $B$ data.

Considering the concatenated data (16S rRNA, ftsZ, and coxA genes), all the distances between supergroups $\mathrm{N}$ and $\mathrm{B}$ are above $3 \%$, and comparable values are obtained between C. cedri (Salamanca) and supergroups B and N. We could not include any other strain from supergroup $\mathrm{M}$ due to unavailability of adequate sequences.

\section{Discussion}

\section{The Infection Dynamics and Supergroups}

The infection rates reported here and those in Augustinos et al. 2011 and Wang et al. 2014 demonstrate a high variability in different geographical areas. Altogether, it seems that the geographical localization of aphids plays a key role in shaping the prevalence of Wolbachia in these organisms. In the present work, the level of infections among the species that harbored Wolbachia was variable (N. podocarpi 100\%, A. spiraecola 44\%, and A. hedera $25 \%$ ), indicating that Wolbachia seem infect either few or most individuals within a species, as previously suggested (Hilgenboecker et al. 2008). Since all the samples and all different DNA extractions of $N$. podocarpi tested were always positive, it is quite possible that all individuals of this species are infected by Wolbachia. Furthermore, $N$. podocarpi sampled in Barcelona as well as Chinese samples were all infected by Wolbachia. Hence, we can postulate that although the supergroups infecting these samples are different, Wolbachia may play an essential role in this species.

Based on phylogenetic analysis, the three supergroups ( $\mathrm{M}, \mathrm{N}$, and B) detected in our samples can be clearly differentiated by $16 \mathrm{~S} r \mathrm{RNA}$ gene sequence data, the same picture emerges in the concatenated phylogenetic tree. The data based on two of the gene markers (gatB and $f t s Z$ ) can separate the supergroup $M$ from supergroups $N$ and B. However, the separation of supergroup $\mathrm{N}$ from supergroups (B 


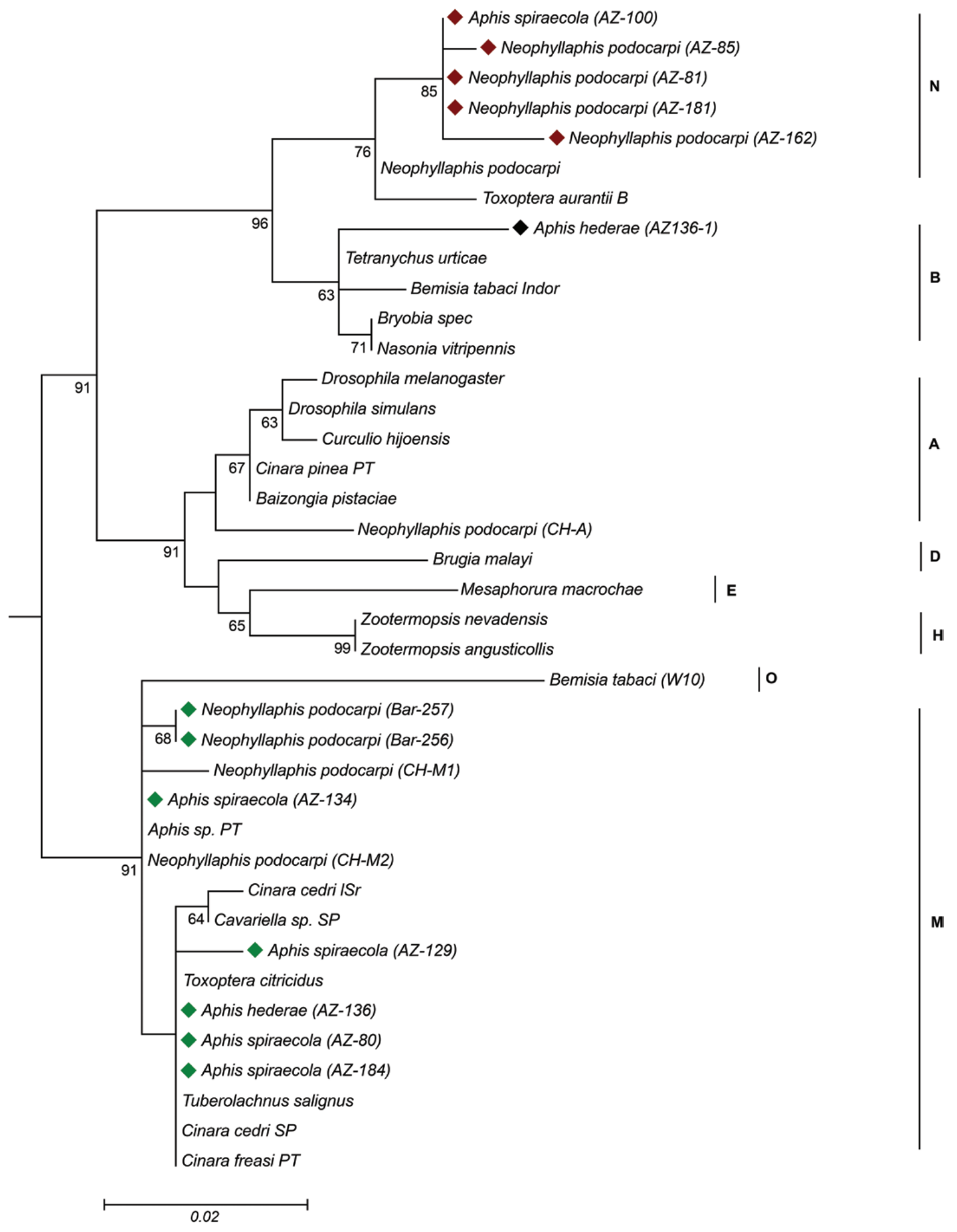

Fig. 1. Wollbachia $16 S$ rRNA phylogenetic tree. The maximum likelihood (ML) phylogenetic tree reconstruction based on $16 S$ rRNA gene fragment (length: $441 \mathrm{bp}$ ) under the GTR+G+I substitution model. The bootstrap values above 60 estimated from 1,000 replicates are indicated. The host species names are used to characterize Wolbachia strains. The samples of the present study are marked.

and/or M) was not clearly supported by MLST data, and the phylogenetic trees demonstrated incongruent grouping (Supp Fig. S2). The occurrence of conflicting results among different gene markers was also reported by Augustinos et al. (2011). It's worth nothing that in whiteflies, some strains of Wolbachia were clustered into a new supergroup $(\mathrm{O})$ by $16 \mathrm{~S} r$ RNA gene analysis; however, the same strains were clustered into supergroup B by several protein- coding genes (Bing et al. 2014), once more indicating the limited reliability of the currently available protein-coding gene markers in supergroup identifications. The samples of the two species of aphids (A. spiraecola 


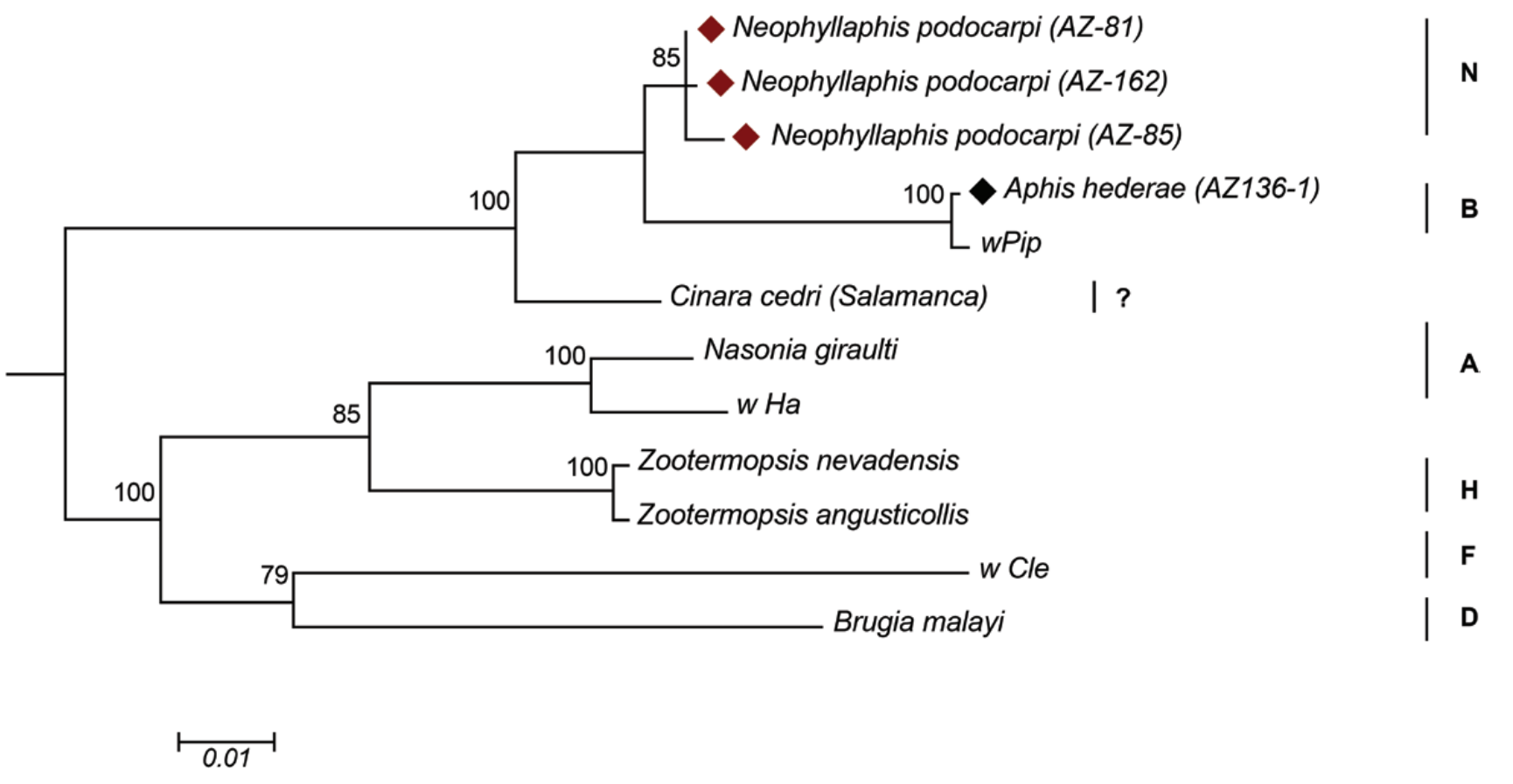

Fig. 2. Wolbachia concatenated phylogenetic tree. The maximum likelihood (ML) phylogenetic tree reconstruction based on concatenated data (16S rRNA, $\mathrm{fts} Z \& \operatorname{cox} A$ ) gene fragments (total length $=1,080 \mathrm{bp}$ ) under the $\mathrm{GTR}+\mathrm{G}+\mathrm{l}$ substitution model. Only the bootstrap values above 60 are shown. The host names characterize Wolbachia strain, wPip (Culex quinquefasciatus), wHa (Drosophila simulans), and wCle (Cimex lectularius).

AZ-86 and N. podocarpi AZ-85), collected from the same host plant, cluster together in $\operatorname{cox} A$ and $\mathrm{fts} Z$ phylogenetic trees (sequences are not available for the other genes). Aphis spiraecola is a polyphagous species but had not been reported in Podocarpus sp. hosts. The high number of $A$. spiraecola individuals sampled from this host plant as well as its absence in the sampling area rules out any accidental sampling, indicating a new adaptation of the aphid species to Podocarpus sp. host plant. N. podocarpi is an ancient, oligophagous aphid associated with conifers and is a native of East Asia and Australia that was introduced to North America and was recently recorded in Europe (Pérez Hidalgo et al. 2015). The time and the mode of introduction of this species together with the pant host are unknown but judging by the size two adjacent plants are much older than the others.

\section{The Origin of the New Supergroups ( $\mathrm{M}$ and $\mathrm{N}$ ) in} Azorean Aphids

Regarding supergroup assignment, the present results reiterate the differential power of the available gene markers in the identification, which is further complicated by the discordance between different genes and strains. Due to lack of information on most of MLST gene sequences in different supergroups, a thorough comparison of our results with other published studies was not possible. Supergroup M is the most abundant supergroup in European and Chinese aphids (Augustinos et al. 2011, Wang et al. 2014) and it was suggested that it was rapidly and recently spreading in all host species in China. Unfortunately, few aphid species have been tested for the presence of Wolbachia in North America and Africa (4 and 2 species, respectively) and data are not available for other regions (Niriganaki et al. 2003, Zytynska and Weisser 2016). On the other hand, supergroup N was only reported in samples from Azores (Augustinos et al. 2011 and present study) where it seems to be as abundant as the supergroup $M$ (present study). Our data show that the main aphid species harboring supergroup $\mathrm{N}$ is $\mathrm{N}$. podocarpi, while A. spiraecola and A. hederae are mainly infected by supergroup $\mathrm{M}$ and occasionally by supergroup $\mathrm{N}$.
The most likely explanation is that $N$. podocarpi was introduced to Azores together with the host plant (Podocarpus sp.). The multiple introduction of plants or propagation of the trees from the first introduction are both plausible. If the latter is correct then N. podocarpus harboring Wolbachia was entered once and then scattered around the island, which would explain that the plants, aphids and are related. The aphids could have harbored supergroup $\mathrm{N}$ at the time of the introduction or it was acquired afterward. The continental species of $N$. podocarpi are infected by supergroup $M$ (Europe) and $\mathrm{M}$ or A (China); therefore, it is unlikely that the host plant was already harboring supergroup $\mathrm{N}$ at the time of its arrival. However, to validate this hypothesis, more data from various parts of the world are needed. It is possible to conclude that N. podocarpi harboring Wolbachia supergroup $\mathrm{N}$ was not introduced to Azores from China (where supergroup $\mathrm{N}$ has not been found). Nevertheless, its introduction from other regions (e.g., Australia) cannot be ruled out. If $N$. podocarpi acquired supergroup $\mathrm{N}$ after its introduction, then it should have been through horizontal transmission from other species.

\section{On Horizontal Transmission}

In arthropods, Wolbachia are recognized as the most successful endosymbionts that manipulate the reproduction of their hosts. Recent studies showed that the bacteria infect about $40 \%$ of species (Hilgenboecker et al. 2008, Zug and Hammerstein, 2012). However, infection is expected to be lost over evolutionary time scale as hosts acquire resistance to the manipulator (Rigaud and Juchault 1993, Hornett et al. 2006, Koehncke et al. 2009).

Is has been proposed that Wolbachia maintenance is an outcome of the rate of horizontal transmission between species as well as the rate of loss within species (Werren et al. 2008, Bailly-Bechet et al. 2017). Evidence for this type of transmission is mainly based on the lack of phylogenetic congruence between Wolbachia and the insect hosts (Schiltuizen and Stouthamer 1997, Vavre et al. 1999, Baldo 
et al. 2008, Raychoudhury et al. 2009). An epidemiological approach indicated that vertical transmission alone is not sufficient for the prevalence of Wolbachia in many hosts and that horizontal transmission has also been occurring between unrelated and phylogenetically distant species (Zug et al. 2012). The horizontal transmission can occur either between closely related hosts (Werren et al. 2008, Zug et al. 2012) or ecologically linked hosts (Sintupachee et al. 2006, Stahlhut et al. 2010). The ecological relatedness and physical contact are considered key factors in strain distribution and horizontal Wolbachia transmission (Engelstädter and Hurst 2006, Gerth et al. 2013). The present data shows the existence of supergroup $\mathrm{N}$ in two phylogenetically different aphids (Aphidinae and Drepanosiphinae) sharing the same host plant (Podocarpus sp.), indicating the possibility of Wolbachia horizontal transmission between the aphids. Plants are already known to mediate the Rickettsia and Wolbachia transmission in whiteflies (Caspi-Fluger et al. 2012, Li et al. 2017).

Although the direction of transmission is not clear, one scenario is the transmission from Neophyllaphis to Aphis, based on the abundance and consistence of supergroup $\mathrm{N}$ infection in the former species. Another question to address is how this supergroup came to infect sporadically Aphis sp., in different islands. One possibility can be through introduction of host plants, together with the aphids and the Wolbachia from one island to another. Another less likely explanation is the existence of a source yet not detected (such as another host plant(s), harboring aphids with Wolbachia supergroup $\mathrm{N}$, parasitoid wasp) that led to the emergence of this supergroup in Azorean aphids.

Augustinos et al. (2011) reported that most aphid species infected belong to Lachninae subfamily and suggested a potential nutritional function for Wolbachia in this group. However, this tendency was detected in neither Chinese populations nor in the present work. Here, we find a close association between Wolbachia and N. podocarpi from Drepanosiphinae subfamily; we also detected another member (Drepanosiphum sp.) of this subfamily to be infected by Wolbachia, although its supergroup was not identified. These results indicate that Wolbachia have an important function in Drepanosiphinae subfamily similar to that reported reported in Lachininae. It will be interesting to test more species from the Drepanosiphinae subfamily for the rate and type of Wolbachia infection and elucidate their involvement in the host life and their interaction with other coendosymbionts.

\section{Supplementary Data}

Supplementary data are available at Environmental Entomology online.

\section{Acknowledgments}

We thank Banco de Germoplasma, ISOPlexis of Universidade da Madeira for laboratory facilities, Fábio Reis and Yashar Sabaz for helping with the graphics and revision. This work was supported by the Foundation for Science and Technology (Project FCT-PTDC/AGR-AAM/108312/2008) to M.K. and by grant BFU2015-64322-C2-1-R (co-financed by FEDER funds and Ministerio de Economía y Competitividad, Spain) to A.L.

\section{Disclosure}

The authors have no conflict of interest to declare.

\section{References Cited}

Ahmed, M. Z., S. J. Li, X. Y. Yin, S. X. Ren, F. M. Jiggins, J. M. Greeff, and B-L. Qiu. 2015. The intracellular bacterium Wolbachia uses parasitoid wasps as phoretic vector for efficient horizontal transmission. PLoS Pathology. 11: e1004672.

Akhoundi, M., A. Cannet, C. Loubatier, J-M. Berenger, A. Izri, P. Mart, and P. Delaunay. 2016. Molecular Characterization of Wolbachia infection in bed bugs (Cimex lectularius) collected from several localities in France. Parasite. 23: 31 .

Augustinos, A. A., D. Santos-Garcia, E. Dionyssopoulou, M. Moreira, A. Papapanagiotou, M. Scarvelakis, V. Doudoumis, S. Ramos, A. F. Aguiar, P. A. V. Borges, et al. 2011. Detection and characterization of Wolbachia infections in natural populations of aphids: is the hidden diversity fully unraveled? PLoS One. 6: e28695.

Bailly-Bechet, M., P. Martins-Simões, G. J. Szöllosi, G. Mialdea, M. Sagot, and S. Charlat. 2017. How long does Wolbachia remain on board? Mol. Biol. Evol. 34: 1183-1193.

Baldo, L., N. A. Ayoub, C. Y. Hayashi, J. A. Russell, J. K. Stahlhut, and J. H. Werren. 2008. Insight into the routes of Wolbachia invasion: high levels of horizontal transfer in the spider genus Agelenopsis revealed by Wolbachia strain and mitochondrial DNA diversity. Mol. Ecol. 17: 557-569.

Baldo, L., J. C. Dunning Hotopp, K. A. Jolley, S. R. Bordenstein, S. A. Biber, R. R. Choudhury, C. Hayashi, M. C. Maiden, H. Tettelin, and J. H. Werren. 2006. Multilocus sequence typing system for the endosymbiont Wolbachia pipientis. Appl. Environ. Microbiol. 72: 7098-7110.

Bing, X. L., W. Q. Xia, J. D. Gui, G. H. Yan, X. W. Wang, and S. S. Liu. 2014. Diversity and evolution of the Wolbachia endosymbionts of Bemisia (Hemiptera: Aleyrodidae) whiteflies. Ecol. Evol. 4: 2714-2737.

Blackman, R.L., and V. P. Eastop. 1984. Aphids on the World's Crops: An Identification Guide. John Wiley \& Sons Ltd., Chichester.

Blackman, R. L., and V. F. Eastop. 1989. Aphids on the World's crops. An identification guide Willey inter science publications. London, UK.

Blackman, R. L., and V. F. Eastop. 1994. Aphids on the World's Trees. An identification and information guide. CABI International, Wallingford, Oxon, UK.

Blackman, R. L., and V. F. Eastop. 2000. Aphids of the world's crops. An identification and information guide. 2nd ed. John Willey \& Sons, Chichester, UK.

Bourtzis, K., S. L. Dobson, Z. Xi, J. L. Rasgon, L. A. Calvitti, A. Moreira, C. Hervé, B. R. Moretti, L. A. Baton, G. L. Hughes, P. Mavingui, and J. R. L. Gilles. 2014. Harnessing mosquito-Wolbachia symbionts for vector and disease control. Acta Tropica. 132(Suppl): 150-163.

Breeuer, J. A., and J. H. Werren. 1990. Microorganisms associated with chromosome destruction and reproductive isolation between two insect species. Nature. 346: 558-560.

Breeuwer, J. A., R. Stouthamer, S. M. Barns, D. A. Pelletier, W. G. Weisburg, and J. H. Werren. 1992. Phylogeny of cytoplasmic incompatibility micro-organisms in the parasitoid wasp genus Nasonia (Hymenoptera: Pteromalidae) based on 16S ribosomal DNA sequences. Insect Mol. Biol. 1: 25-36.

Caspi-Fluger, A., M. Inbar, N. Mozes-Daube, N. Katzir, V. Portnoy, E. Belausov, M. S. Hunter, and E. Zchori-Fein. 2012. Horizontal transmission of the insect symbiont Rickettsia is plant-mediated. Proc. Biol. Sci. 279: 1791-1796.

Chen, D. Q., C. B. Montllor, and A. H. Purcell. 2000. Fitness effects of two facultative endosymbiotic bacteria on pea aphids. Acyrthosiphon pisum, and the blue alfalfa aphids, A. kondoi. Entomol. Exp. Appl. 95: 315-323.

De Clerck, C., A. Fujiwara, P. Joncour, S. Léonard, M. L. Félix, F. Francis, M. H. Jijakli, T. Tsuchida, and S. Massart. 2015. A metagenomic approach from aphid's hemolymph shed light on the potential roles of co-existing endosymbionts. Microbiome. 3: 1-11.

Engelstädter, J., and G. Hurst. 2006. The dynamics of parasite incidence across host species. Evol. Ecol. 20: 603-616.

Gerth, M. 2016. Classification of Wolbachia (Alphaproteobacteria, Rickettsiales): no evidence for a distinct supergroup in cave spiders. Infect. Genet. Evol. 43: 378-380.

Gerth, M., J. Rothe, and C. Bleidorn. 2013. Tracing horizontal Wolbachia movements among bees (Anthophila): a combined approach using multilocus sequence typing data and host phylogeny. Mol. Ecol. 22: 6149-6162.

Glowska, E., A. Dragun-Damian, M. Dabert, and M. Gerth. 2015. New Wolbachia supergroups detected in quill mites (Acari: Syringophilidae). Infect. Genet. Evol. 30: 140-146.

Gómez-Valero, L., M. Soriano-Navarro, V. Pérez-Brocal, A. Heddi, A. Moya, J. M. García-Verdugo, and A. Latorre. 2004. Coexistence of Wolbachia with 
Buchnera aphidicola and a secondary symbiont in the aphid Cinara cedri. J. Bacteriol. 186: 6626-6633.

Guo, J., S. Hatt, K. He, J. Chen, F. Francis, and Z. Wang. 2017. Nine facultative endosymbionts in aphids. A review. J. Asia-Paci. Entomol. 20: 794-801.

Hall, T. A. 1999. "BioEdit": a user-friendly biological sequences alignment editor and analysis program for Windows 95/98/NT". Nucl. Acid Symp. Ser. 41: 95-98.

Hansen, A. K., and N. A. Moran. 2011. Aphid genome expression reveals host-symbiont cooperation in the production of amino acids. Proc. Natl. Acad. Sci. USA. 108: 2849-2854.

Heyworth, E. R., and J. Ferrari. 2015. A facultative endosymbiont in aphids can provide diverse ecological benefits. J. Evol. Biol. 28: 1753-1760.

Hilgenboecker, K., P. Hammerstein, P. Schlattmann, A. Telschow, and J. H. Werren. 2008. How many species are infected with Wolbachia?-A statistical analysis of current data. FEMS Microbiol. Lett. 281: $215-220$.

Hornett, E. A., S Charlat, Duplouy, A. M. R., N. Davies, G. K. Roderick, N. Wedell, and G. D. D. Hurst. 2006. Evolution of male-killer suppression in a Natural Population. PLoS Biol 4: e283.

Hosokawa, T., R. Koga, Y. Kikuchi, X. Y. Meng, and T. Fukatsu. 2010. Wolbachia as a bacteriocyte-associated nutritional mutualist. Proc. Natl. Acad. Sci. USA. 107: 769-774.

Kimura, M. 1980. A simple method for estimating evolutionary rates of base substitutions through comparative studies of nucleotide sequences. J. Mol. Evol. 16: 111-120.

Koehncke, A., A. Telschow, J. H. Werren, and P. Hammerstein. 2009. Life and death of an influential passenger: Wolbachia and the evolution of CI-modifiers by their hosts. PLoS ONE. 4: e4425.

Koga, R., T. Tsuchida, and T. Fukatsu. 2003. Changing partners in an obligate symbiosis: a facultative endosymbiont can compensate for loss of the essential endosymbiont Buchnera in an aphid. Proc. Biol. Sci. 270: 2543-2550.

Koga, R., T. Tsuchida, M. Sakurai, and T. Fukatsu. 2007. Selective elimination of aphid endosymbionts: effects of antibiotic dose and host genotype, and fitness consequences. FEMS Microbiol. Ecol. 60: 229-239.

Lamelas, A., M. J. Gosalbes, A. Manzano-Marín, J. Peretó, A. Moya, and A. Latorre 2011. Serratia symbiotica from the aphid Cinara cedri: a missing link from facultative to obligate insect endosymbiont. Plos Genet. 7: e1002357.

Lamelas, A., V. Pérez-Brocal, L. Gómez-Valero, M. J. Gosalbes, A. Moya, and A. Latorre. 2008. Evolution of the secondary symbiont "Candidatus serratia symbiotica" in aphid species of the subfamily Lachninae. Appl. Environ. Microbiol. 74: 4236-4240.

Latorre, A., and A. Manzano-Marín. 2017. Dissecting genome reduction and trait loss in insect endosymbionts. Ann. N. Y. Acad. Sci. 1389: 52-75.

Latorre, A., A. Moya, and F. J. Ayala. 1986. Evolution of mitochondrial DNA in Drosophila subobscura. Proc. Natl. Acad. Sci. USA. 83: 8649-8653.

Leclair, M., S. Polin, T. Jousseaume, J. C. Simon, A. Sugio, S. Morlière, T. Fukatsu, T. Tsuchida, and Y. Ourteman. 2016. Consequences of coinfection with protective symbionts on the host phenotype and symbiont titres in the pea aphid system. Insect Sci. 24: 798-808. 1-11.

Li, S. J., M. Z. Ahmed, N. Lv, P. Q. Shi, X. M. Wang, J. L. Huang, and B. L. Qiu. 2017. Plant-mediated horizontal transmission of Wolbachia between whiteflies. Microb. Ecol. 11: 1019-1028.

Lo, N., C. Paraskevopoulos, K. Bourtzis, S. L. O’Neill, J. H. Werren, S. R. Bordenstein, and C. Bandi. 2007. Taxonomic status of the intracellular bacterium Wolbachia pipientis. Int. J. Syst. Evol. Microbiol. 57: 654-657.

Łukasik, P., M. van Asch, H. Guo, J. Ferrari, and H. C. Godfray. 2013a. Unrelated facultative endosymbionts protect aphids against a fungal pathogen. Ecol. Lett. 16: 214-218.

Eukasik, P., H. Guo, M. van Asch, J. Ferrari, and H. C. Godfray. 2013b. Protection against a fungal pathogen conferred by the aphid facultative endosymbionts Rickettsia and Spiroplasma is expressed in multiple host genotypes and species and is not influenced by co-infection with another symbiont. J. Evol. Biol. 26: 2654-2661.

Maddison, D. R., and W. P. Maddison. 2000. MacClade 4: analysis of phylogeny and character evolution. Sinauer Associates, Sunderland, MA.
Manzano-Marín, A., and A. Latorre. 2014. Settling down: the genome of Serratia symbiotica from the aphid Cinara tujafilina zooms in on the process of accommodation to a cooperative intracellular life. Genome Biol. Evol. 6: 1683-1698.

Moya, A., J. Peretó, R. Gil, and A. Latorre. 2008. Learning how to live together: genomic insights into prokaryote-animal symbioses. Nat. Rev. Genet. 9: 218-229.

Nikoh, N., T. Hosokawa, M. Moriyama, K. Oshima, M. Hattori, and T. Fukatsu. 2014. Evolutionary origin of insect - Wolbachia nutritional mutualism. Proc. Natl. Acad. Sci. 111: 10256-10262.

Nirgianaki, A., G. K. Banks, D. R. Frohlich, Z. Veneti, H. R. Braig, T. A. Miller, I. D. Bedford, P. G. Markham, C. Savakis, and K. Bourtzis. 2003. Wolbachia infections of the whitefly Bemisia tacbaci. Curr. Microbiol. 47: 93-102.

Oliver, K. M., J. A. Russell, N. A. Moran, and M. S. Hunter. 2003. Facultative bacterial symbionts in aphids confer resistance to parasitic wasps. Proc. Natl. Acad. Sci. USA. 100: 1803-1807.

Oliver, K. M., N. A. Moran, and M. S. Hunter. 2005. Variation in resistance to parasitism in aphids is due to symbionts not host genotype. Proc. Natl. Acad. Sci. USA. 102: 12795-12800.

Oliver, K. M., P. H. Degnan, G. R. Burke, and N. A. Moran. 2010. Facultative symbionts in aphids and the horizontal transfer of ecologically important traits. Annu. Rev. Entomol. 55: 247-266.

Oliver, K. M., A. H. Smith, and J. A. Russell. 2014. Defensive symbiosis in the real world-advancing ecological studies of heritable, protective bacteria in aphids and beyond. Funct. Ecol. 28: 341-355.

O'Neill, S. L., A. A. Hoffmann, and J. H. Werren. (ed). 1997. Influential passengers: inherited microorganisms and arthropod reproduction. Oxford University Press, UK.

Pérez-Brocal, V., R. Gil, S. Ramos, A. Lamelas, M. Postigo, J. M. Michelena, F. J. Silva, A. Moya, and A. Latorre. 2006. A small microbial genome: the of a long symbiotic relationship? Science. 314: 312-313.

Pérez Hidalgo, N., C. Hernández-Castellano, and F. Garcia Figueres. 2015 First record of Neophyllapis podocarpi Takahashi (Hemiptera: Aphididae) in the Iberian Peninsula. EPPO Bulletin OEPP. 45: 1-3.

Perilla-Henao, L. M., and C. L. Casteel. 2016. Vector-Borne bacterial plant pathogens: Interactions with Hemipteran Insects and Plants. Front. Plant Sci. 7: 1163

Polin, S., J. C. Simon, and Y. Outreman. 2014. An ecological cost associated with protective symbionts of aphids. Ecol. Evol. 4: 826-830.

Raychoudhury, R., L. Baldo, D. C. Oliveira, and J. H. Werren. 2009. Modes of acquisition of Wolbachia: horizontal transfer, hybrid introgression, and codivergence in the Nasonia species complex. Evolution. 63: 165-183.

Rigaud, T., and P. Juchault. 1993. Conflict between feminizing sex ratio distorters and an autosomal masculinizing gene in the terrestrial isopod Armadillidium vulgare Latr. Genetics. 133: 247-252.

Russell, J. A., A. latorre, B. Sabater-Munoz, A. Moya, and N. A. Moran. 2003. Side-stepping secondary symbionts: widespread horizontal transfer across and beyond the Aphidoidea. Mol. Ecol. 12: 1061-1075.

Russell, J. A., S. Weldon, A. H. Smith, K. L. Kim, Y. Hu, P. Łukasik, S. Doll, I. Anastopoulos, M. Novin, and K. M. Oliver. 2013. Uncovering symbiont-driven genetic diversity across North American pea aphids. Mol. Ecol. 22: 2045-2059.

Saridaki, A., and K. Bourtzis. 2010. Wolbachia: more than just a bug in insects genitals. Curr. Opin. Microbiol. 13: 67-72.

Scarborough, C. L., J. Ferrari, and H. C. J. Godfray. 2005. Aphid protected from pathogen by Endosymbiont. Science. 1310: 1781.

Schilthuizen, M., and R. Stouthamer. 1997. Horizontal transmission of parthenogenesis-inducing microbes in Trichogramma wasps. Proc. Biol. Sci. 264: 361-366.

Simon, J. C., M. Sakurai, J. Bonhomme, T. Tsuchida, R. Koga, and T. Fukatsu. 2007. Elimination of specialized facultative symbionts does not affect the reproductive mode of its aphid host. Ecol. Entomol. 32: 296-301.

Sintupachee, S., J. R. Milne, S. Poonchaisri, V. Baimai, and P. Kittayapong. 2006. Closely related Wolbachia strains within the pumpkin arthropod community and the potential for horizontal transmission via the plant. Microbial. Ecol. 51: 294-301. 
Stahlhut, J. K., C. A. Desjardins, M. E. Clark, L. Baldo, J. A. Russell, and J. H. Werren. 2010. The mushroom habitat as an ecological arena for global exchange of Wolbachia. Mol. Ecol. 19: 1940-1952.

Stouthamer, R., R. F. Luck, and W. D. Hamilton. 1990. Antibiotics cause parthenogenetic Trichogramma (Hymenoptera/Trichogrammatidae) to revert to sex. Proc. Natl. Acad. Sci. USA. 87: 2424-2427.

Stouthamer, R., J. A. Breeuwert, R. F. Luck, and J. H. Werren. 1993. Molecular identification of microorganisms associated with parthenogenesis. Nature. 361: 66-68

Stouthamer, R., J. A. Breeuwer, and G. D. Hurst. 1999. Wolbachia pipientis: microbial manipulator of arthropod reproduction. Ann. Rev. Microbiol. 53: 71-102.

Tamura, K., G. Stecher, D. Peterson, A. Filipski, and S. Kumar. 2013. MEGA6: molecular evolutionary genetics analysis version 6.0. Mol. Biol. Evol. 30: 2725-2729.

Thompson, J. D., D. G. Higgins, and T. J. Gibson. 1994. CLUSTAL W: improving the sensitivity of progressive multiple sequence alignment through sequence weighting, position-specific gap penalties and weight matrix choice. Nucleic Acids Res. 22: 4673-4680.

Tsuchida, T., R. Koga, and T. Fukatsu. 2004. Host plant specialization governed by facultative symbionts. Science. 303: 1989.
Vavre, F., F. Fleury, D. Lepetit, P. Fouillet, and M. Boulétreau. 1999. Phylogenetic evidence for horizontal transmission of Wolbachia in host-parasitoid associations. Mol. Biol. Evol. 16: 1711-1723.

Wang, Z., X-M. Su, J. Wen, L-Y. jiang, and G-X. Qiao. 2014. Widespread infection and diverse infection patterns of Wolbachia in Chinese aphids. Insect Sci. 21: 313-325.

Wang, G. H., L. Y. Jia, J. H. Xiao, and D. W. Huang. 2016. Discovery of a new Wolbachia supergroup in cave spider species and the lateral transfer of phage WO among distant hosts. Infect. Genet. Evol. 41: 1-7.

Werren, J. H., L. Baldo, and M. E. Clark. 2008. Wolbachia: master manipulator of invertebrate biology. Nat. Rev. Microbiol. 6: 741-751.

Zhou, W., F. Rousset, and S. O’Neil. 1998. Phylogeny and PCR-based classification of Wolbachia strains using wsp gene sequences. Proc. Biol. Sci. 265: 509-515.

Zug, R., and P. Hammerstein. 2012. Still a host of hosts for Wolbachia: analysis of recent data suggests that $40 \%$ of terrestrial arthropod species are infected. PLoS One. 7: e38544.

Zug, R., A. Koehncke, and P. Hammerstein. 2012. Epidemiology in evolutionary time: the case of Wolbachia horizontal transmission between arthropod host species. J. Evol. Biol. 25: 2149-2160.

Zytynska, S. E., and W. W. Weisser. 2016. The natural occurrence of secondary bacterial symbionts in aphids. Ecol. Entomol. 41: 13-26 